Language and Cognition 13 (2021), 291-321. doi:10.1017/langcog.2021.5

(C) The Author(s), 2021. Published by Cambridge University Press. This is an Open Access article, distributed under the terms of the Creative Commons Attribution licence (http:// creativecommons.org/licenses/by/4.0/), which permits unrestricted re-use, distribution, and reproduction in any medium, provided the original work is properly cited.

\title{
Limitations on the role of frequency in L2 acquisition*
}

\author{
CHRISTIANE VON STUTTERHEIM \\ Heidelberg University
}

MONIQUE LAMBERT

Université Paris 8

A N D

\author{
JOHANNES GERWIEN \\ Heidelberg University
}

(Received 28 fuly 2020 - Revised 10 February 2021 - Accepted 22 February 2021 First published online 29 March 2021)

\begin{abstract}
A B S T R A C T
In the context of theories of statistical learning, frequency of encounter is viewed as a major driving force in L2 acquisition. The present paper challenges this position with respect to core components at the level of language competence which relate to language-specific patterns in cognitive construal. Empirical evidence from very advanced L2 speakers (L1 French, L2 English and L2 German) shows that forms and constructions which are highly frequent in the target languages in the expression of motion events are not used in a target-like form by L2 speakers. The study shows how the basis for language use which is not target-like lies at the level of event construal: conceptual frames, which are language-specific and are deeply anchored in the course of L1 acquisition, drive allocation of attention and the extraction of forms in L2 acquisition. Findings in the domain of spatial cognition show that motion event frames based on the L1 take precedence over frequency of occurrence of forms in the target language as a factor in L2 use.
\end{abstract}

KEYWORDS: L2 acquisition, motion events, frequency, event construal, selective attention

[*] Address for correspondence: C.v.Stutterheim, Institut für Deutsch als Fremdsprachenphilologie, Plöck 55, D 69117 Heidelberg. e-mail: stutterheim@idf.uni-heidelberg.de 


\section{Introduction}

Studies on frequency of input as a relevant factor in L2 ${ }^{1}$ acquisition go back to the early phases of systematic L 2 research. This line of enquiry faded into the background, however, with the emergence of universalism and its domination of the field (Schachter, 1988; Menn \& Bastiaanse, 2016). It has, however, come into focus as an explanatory factor, motivated by theories of usage-based learning as well as probabilistic approaches in the context of machine learning.

The aim of the present study is to challenge the role of frequency as the major factor in L2 acquisition on the way to acquiring full competence - full competence which includes comprehension and creative language use. "It's all counting" (Ellis, 2002, p. 148) or "language is a statistical accumulation of experiences" (Siyanova-Chanturia \& Spina, 2015, p. 553) - these are claims which will come under scrutiny. If 'experience' is viewed as the basis for all kinds of learning, what does 'experience' entail in order to be transformed into the relevant knowledge structures and put into practice? There has been a longstanding discussion on the different cognitive processes which influence and determine language acquisition: attention, awareness, conscious detection, storage in memory - theoretical constructs which expand on what constitutes experience. Robinson (1995) provides a still valid, comprehensive overview of theories that attempt to model the interaction between these different components of the relevant cognitive capacities. He concludes that "the nature of the interaction between cognitive resources during information processing and language learning is little understood" (1995, p. 318). Twenty-five years and countless studies later we can draw on a wide range of empirical details concerning L2 acquisitional processes. However, our understanding of L2 acquisition is still far from complete. One of the problems lies in the often reductionist approach in L2 acquisition research. As will be discussed below, recent studies on the role of frequency in language acquisition focus on acquisition as the storage of linguistic material and production in scripted contexts. Little attention is placed on L2 competence in relation to creative language use. A word recognition test or a frequency judgment test might show that learners have acquired lexical items, idiomatic expressions, or knowledge on collocations of certain items. When it comes to the underlying factors which are highly language-specific in actual language use, however, L2 speakers may fail to follow the specific sets of principles that native speakers apply when linking linguistic categories and conceptual representation. There are underlying components of language competence that cannot be transmitted via frequent experience in the perception of forms because they are covert. This holds for form-function relations that encompass larger conceptual units such

[1] The term L2 is used in reference to languages other than a person's mother tongue. It also includes cases of multiple foreign language competence. 
as event frames or object schemata. Robinson pointed to this domain as follows: "Further, when tasks require predominantly conceptually-driven processing, the availability of knowledge schemas to organise perception and to direct attention to relevant aspects of the stimulus domain should also be important. The extent to which preexisting representations are available will determine the efficiency of attentional allocation” (1995, p. 320). We will elaborate on this claim in the present study by looking into the role of preexisting representations as internal PULL-FACTORS in relation to external P USH -F A C T ORS determined by properties of the input. On these grounds, frequency of 'experience' will thus be placed in the larger context of theories on language and cognitive processing.

The idea that external and internal factors have to come together in L2 acquisition is certainly not new. However, current models set complex internal factors largely aside by claiming that language learning is exemplar-based at all levels (Ellis, 2002, p. 166). Whilst noting that L2 acquisition is filtered through the lens of the L1, Wulff and Ellis (2018, p. 50) state in conclusion that "second language learners employ the same statistical learning mechanisms that they employed when they acquired their first language”. On the basis of an empirical study on a central domain of human cognition - spatial categories - it can be shown that there is a crucial difference between the two types of acquisition given the fact that conceptual frames which have become deeply anchored in the course of L1 acquisition may override frequency effects.

\section{State of the art}

\subsection{PROCESSES AT THE BASE OF LANGUAGE ACQUISITION}

Usage-based theories hold that language learning, both in first and second language, relies on a range of implicit cognitive mechanisms such as association, sensitivity to frequency of occurrence and to strings of occurrences (chunking), as well as the extraction of statistical regularities and inductive generalisation of collocational dependencies. The assumption is that speakers as 'intuitive statisticians' are highly sensitive to frequency in the use of linguistic expressions. In the case of language acquisition, frequency of occurrence is viewed as a major determinant (Ellis, 2003; overview in Kartal \& Sarigul, 2017). According to this point of view, each repetition will increase the strength of the connections of relevant features, reinforce representation in memory and thus automatic retrieval. The resulting knowledge is stored in a mental lexicon "in which abstract grammatical patterns and lexical instantiations of those patterns are jointly included" ('Tummers, Heylen, \& Geearts, 2005, pp. 228-229). This idea is elaborated further in the theoretical framework of Construction Grammar (e.g., Goldberg, 2006; Ellis, 2013). "Research 
in psycholinguistics demonstrates that generally, the more frequently a construction (or combination of constructions) is experienced, the earlier it is acquired and the more fluently it is processed" (Wulff \& Ellis, 2018, p. 40). ${ }^{2}$

In contrast to earlier studies on frequency effects in L2 acquisition in which individual morphemes and lexical items were under focus (Larsen-Freeman, 1976; for reviews see Gass \& Mackey, 2002; Larsen-Freeman, 2002), the effect of frequency of experience on acquisition has been extended to combinations of linguistic units. Learners are not only sensitive to the frequency with which expressions occur but also to their distribution. Spoken language is constituted by a large number of highly frequent combinations of specific words, up to $50 \%$ according to an estimation by Erman and Warren (2000). These combinations range from collocations over conventional expressions, fixed expressions, and idioms to proverbs. Fixed or prefabricated expressions of this kind have motivated an important area in L1 and L2 research in investigating how they are processed and represented in the brain (cf. Ellis et al., 2015; SiyanovaChanturia \& Pellicer-Sanchez, 2019, for reviews). Given the diversity of the linguistic structures investigated, the following overview of the studies will be limited to those on the expression of multiword expressions.

\subsection{OVERVIEW OF STUDIES ON THE ROLE OF FREQUENCY IN MULTIWORD PROCESSING}

The general assumption underlying frequency effects in psycholinguistic research is that there is a relationship between the frequency of items and constructions and speed in reaction time, as well as accuracy in relation to the use of these linguistic forms. Investigations focus on the implicit cognitive mechanisms in comprehension as they unfold in real time. Results for readings times show frequency effects (McDonald \& Shillcock, 2003; Ellis, Frey \& Jalkanen, 2009). Studies on memory capacity revealed that performance varied in accordance with the factor frequency (Tremblay et al., 2011). Another line of research focused on grammaticality judgement tasks (Arnon \& Snider, 2010). Subjects processed frequent combinations faster than less frequent ones. In the same vein, eye-movement studies showed that the fixation time on each word in reading is a function of its frequency and of the forward transitional probability (McDonald \& Shillcock, 2003). These and similar L1 studies that test a range of processing mechanisms offered multifaceted evidence that speakers are sensitive to the frequency with which constructions/ collocations occur: frequent collocations are perceived, recognised, retrieved,

[2] In the following the term construction is used to refer to syntactic patterns that integrate more than one constituent, e.g., noun phrase verb + prepositional phrase; at the word level we refer to lexical items, e.g., manner verb. 
and recalled faster, thus reflecting their level of entrenchment and pointing to a holistic representation in the mental lexicon (cf. overview in Ellis, 2002; Gries \& Divjak, 2012; for discussion Bley-Vroman, 2002). The same standard paradigms are used to systematically study frequency effects in L2 speakers and in comparisons of native and non-native speakers.

\subsection{FREQUENCY EFFECTS: L 2 SPEAKERS}

L2 studies relevant in the given context investigated the extent to which second language speakers show the same sensitivity to frequency of constructions/ collocations as native speakers of their T A R G E T L A N G U A G E (TL). Jiang and Nekrasova (2007) studied frequency effects in a timed judgement task. L2 English and English L1 speakers both responded faster to frequent in contrast to non-frequent collocations which were matched for length (to tell the truth vs. to tell the price). A study conducted by Ellis, Simpson-Vlach, and Maynard (2008) tested how frequency, as well as degree of cohesiveness, affect accuracy and fluency when processing sequences of formulaic academic speech and writing. Evidence from the different experiments, which tested recognition and production, converged in showing that native as well as non-native speakers process frequent formulas faster. However, non-native speakers were predominantly influenced by frequency effects at the item level, whereas native speakers were predominantly affected by association-strength effects. In a follow-up study, Simpson-Vlach and Ellis (2010) further investigated the role of frequency of collocations on a large range of processing mechanisms including reading time, voice onset time, articulation time, priming procedures, and plausibility of occurrence in the real world. Results confirmed previous findings showing that frequent formulas are processed faster in all tests. Arnon and Snider (2010) analysed the impact of frequency on combinations which differed along a continuous frequency scale. Using a phrasal decision task on fourword combinations, don't have to worry vs. don't have to wait, regression analysis showed that response times were inter-related with the frequency of the strings, thus supporting the assumption of learners' sensitivity to the frequency of collocations. Vilkaite and Schmitt (2017) compared reading times of adjacent vs. non-adjacent collocations vs. controls obtained from L2 speakers of English with those obtained from L1 speakers (such as provide (some of the) information vs. compare (some of the) information) using eyetracking. Adjacent collocations were read faster in both the L1 and L2 groups, but a higher speed in non-adjacent collocation processing was manifest in the L1 group only.

Studies testing sensitivity to frequency of collocations in relation to levels of competence in L2 are scarce. Siyanova-Chanturia, Conklin, and van Heuven (2011) used an eye-tracking paradigm to examine the comprehension of fixed 
phrasal combinations, e.g., time and money vs. their reversed forms money and time. They found frequency effects both in L1 and in highly competent L2 speakers, but not in speakers with a lower proficiency. Hernández, Costa, and Arnon (2016) tested the impact of competence in the L2 (upper intermediate vs. lower advanced) and type of exposure (immersion vs. classroom) on frequency effects. Based on the methodology and material used in Arnon and Snider (2010), they found that both native and non-native speakers, irrespective of level and exposure, manifested equal sensitivity to the frequency of multiword units. L1 influence on processing idioms and collocations in the L 2 was recently investigated by Conklin and Carroll (2018). According to the authors, idioms and collocations of the L1s are activated and influence processing of their L 2 counterparts on the basis of relations involving form and meaning. When meaning and form are shared, processing is facilitated. However, if form but not meaning, or the reverse, do not overlap, then processing is more difficult.

\subsection{DISCUSSION OF PREVIOUS STUDIES}

In a review paper, Ellis (2002) summarises findings on L2 acquisition at different levels of linguistic complexity with the claim "it is all counting" (2002, p. 148). However, we hold that there are a number of major limitations on the validity of such a generalised statement which are rooted in our understanding of what it means to acquire a language and what language competence actually encompasses. As the overview shows, the studies on frequency effects are limited with regard to both the type of linguistic material and levels of language processing, in that focus is placed on idiomatic expressions and highly frequent collocations ${ }^{3}$ in scripted contexts. These components of linguistic knowledge were tested in comprehension, accessibility, and adequacy/grammaticality judgements. In most of these formats, however, L2 speakers do not have to activate conceptual representations in response to a novel stimulus and link these with their available L2 lexical and grammatical repertoire. It thus remains untested in how far speakers are actually able to activate their L2 knowledge in a way that meets patterns of cognitive construal in the target language. There is more to language competence than an inventory of lexical items, their collocations, and constructions. This can be readily illustrated by looking at two of the most frequent words in the English language: the articles the and $a$. These forms are certainly acquired from very early on in L2 acquisition. However, the principles which govern their use in context and which form part of the linguistic knowledge of a native speaker are

[3] We do not take into account the numerous studies on single items, phonology, and spelling in the given context. 
extremely difficult to uncover and acquire (e.g., Jarvis, 2002). Components of language competence of this kind can only be investigated with studies on creative language use. Although this is one of the central tenets of usage-based approaches (cf. the discussion in Tyler, 2010), empirical research on contextually adequate use of (complex) linguistic forms is still rare.

\section{The present approach}

\subsection{OVERVIEW}

In L2 acquisition new TL forms meet consolidated conceptual structures which in terms of abstract categorical knowledge will include object categories as well as event or situation frames, or schemata (cf. Fillmore, 1977; Langacker, 1987; overview in Croft \& Cruse, 2004). The conceptual framing acquired in the course of L1 acquisition which manifests in language-specific patterns of event construal may impede acquisition and use of frequent and easily processed strings of words in the L2 (cf. the discussion on conceptual transfer Pavlenko, 2011). This can be attributed to the fact that the processes are subject to a push-and-pull mechanism based on both external and internal factors: in order to achieve L2 competence, which includes cognitive framing, the two forces have to work jointly in opening the gateway for intake. The key concept in this process is selective attention (cf. 'windowing of attention', Talmy, 1994). In order to process information and to store it in long-term memory it has to be attended to consciously or unconsciously.

There are two types of factors that function as a filter on processes involving selective attention and its allocation in acquisition, as well as in creative language use: internal factors, based on existing conceptual representations, function as conceptual preconditions which lead to the search for specific expressive devices for use in language production. Communicative requirements, framed in specific conceptual structures, guide attention and thereby block or promote the reception and storage of new forms. Given the fact that event frames and object schemata take shape in the course of L1 acquisition, this leads to languagespecific moulding of conceptual content. This will thus accord salience to specific features while defocusing others. Conceptual framing and pre-existing representations constitute a driving force in the selection and use of linguistic material.

External factors, as manifested in the input, can be attributed to different features, such as the frequency with which an element occurs, phonological markedness, and syntactic markedness, but also communicative relevance as well as contingency in form-function relations (cf. Wulff \& Ellis, 2018). Salience in the input will trigger attention (cf. the concept of 'noticing' in Robinson 1995, p. 318) as a precondition for perception, followed by intake and finally storage in memory. However, as we will show in the present study on the expression of motion events even very advanced L2 speakers may not use forms which are 
highly frequent, and which are often the only option in the TL to describe a given situation. This phenomenon calls the determining role of external factors in a strict sense into question. The present study will investigate the impact of conceptual framing in its role as a hurdle for native-like L2 use. Our approach focuses on the domain of motion events which provides a window on the range of relevant conceptual interdependencies.

\subsection{THEORETICAL AND EMPIRICAL BACKGROUND}

The conceptualization and description of motion events has been studied extensively over decades with a clear consensus across different theoretical camps that languages differ in the way in which motion events are represented. Motion events are conceptual units which result from processes of input segmentation and information selection that operate on the continuous stream of perception (Zacks \& Tversky, 2001; Gerwien \& Stutterheim, 2018).

Talmy (2000) laid the groundwork in capturing relevant features in a typology of spatial semantics. Numerous empirical studies based on this typology show how speakers of different languages follow specific principles in framing motion events (Slobin, 2004). If a speaker follows a verb-framed pattern, as in French for example, information will be selected on the figure in motion with respect to its orientation and a potential goal, as in the utterance une femme se dirige vers une église 'a woman directs herself towards a church'. Speakers of a satellite-framed language, such as German, select information on the figure which relates to manner of motion, with information on contours of the ground traversed and a potential goal, leading to utterances such as eine Frau läuft eine Straße entlang zu einer Kirche 'a woman walks along a street to a church'. The cross-linguistic comparisons are clear: speakers of different languages select different components of the situation for verbalization.

The research question that followed from these studies addressed the relationship between linguistically coded categories and cognitive processes. The theory formulated as T H I N K I N G F O R S P E A K I N G (Slobin, 1996) holds that spatial conceptualisation, based on the means used to encode spatial relations between entities, is tuned to the linguistic system used in encoding. However, it is left open as to whether there is an a-modal, or possibly universal underlying cognitive structure in the representation of motion events. Experimental research then set out to tackle this question based on studies of non-verbal cognitive processing of motion events (memory performance, non-verbal segmentation tasks, visual attention, EEG categorization; cf. Flecken, Stutterheim, \& Carroll, 2014; Flecken et al., 2015a; Gerwien \& Stutterheim, 2018; Stutterheim et al., 2012). The findings present evidence of processes that are language-specific. They allow for the conclusion that event framing, as shaped by a specific language, leads to deeply entrenched patterns which 
function at a high level of abstraction and allow highly automatized and rapid cognitive functioning in order to meet the requirements of communication and interaction within a complex reality.

The line of argumentation in the current study is based on a wide range of cross-linguistic studies on the verbalisation of motion events (Carroll et al., 2012; Stutterheim et al., 2012, Flecken et al., 2015b; Stutterheim et al., 2020). For example, in a study contrasting German and French (Gerwien \& Stutterheim, 2018), participants were asked to describe situations presented in video clips. The results show significant differences between the two groups, reflecting language-specific contrasts in spatial cognition as the critical factor: French speakers, when expressing direction, proceed on the basis of spatial concepts based on the figure (direction, orientation) in motion event construal. Significantly, these concepts are expressed in verbs, e.g., avancer 'to advance', se diriger 'to direct oneself' (Carroll, 2000). If there is no evidence on the orientation of the figure or the direction taken, French speakers resort to a different pattern in conceptualization and view a situation of this type as 'frozen motion'. This encompasses manner of motion in the verb combined with forms which encode the location of the figure only (to walk on a road). In the following the term S T A T I O N A R Y M O T I O N will be used, borrowed from Talmy (2000). In contrast to French, speakers of German generally draw on ground-based properties in the formation of an event unit ${ }^{4}$ (cf. Pourcel \& Kopecka, 2005; Berthele, 2013; Durst-Anderson, Smith, \& Nedergaard Thomsen, 2013).

Due to extensive linguistic input in the course of L1 acquisition, languagespecific conceptualisation patterns emerge and are stored in long-term memory, represented as event frames in the case of motion events. The frames form clusters of abstract concepts, whereby the basis for selection is anchored in the relevant language-specific constraints. Activation of the frames entails selective attention to different aspects in the flow of information as well as implicational relations between the relevant components. Automatic cognitive functioning draws on these frames. An L2 learner meets the new language equipped with deeply entrenched knowledge structures.

\section{Empirical study}

In order to address our guiding question concerning the role of frequency for L2 acquisition, we designed an empirical study in which native speakers and

[4] A situation showing a girl running along a path into a station was segmented into two units by French speakers, corresponding to une jeune fille court et entre dans une gare 'a young girl runs and enters a station'. German speakers, by contrast, do not segment the film clip in this way: ein Mädchen rennt (einen Weg entlang) in einen Bahnhof'a young girl runs (along a path) into a station'. 
advanced L2 speakers verbalised motion events spontaneously. We argue that the responses provided by the subjects form a small-scale, but highly reliable, corpus which indicates specifically and unambiguously the frequency of use of specific lexical items and grammatical structures, as well as activated event frames in the domain of motion event encoding. By creating a corpus in this way, we ensure that the items being counted for comparing frequencies between groups relate to identical situations and tasks (unscripted verbalisations). We consider this to be a valid alternative approach to retrieving frequencies of occurrence from large, but 'messy' corpora, i.e., where context and actual reading cannot be controlled for. The analysis of the frequency of occurrence of lexical items, structures, and frames targets two more specific questions: (a) How much do very advanced speakers of an L2 use the most frequent forms used by native speakers when expressing information on motion events? (b) If L2 speakers use forms which are frequent in the TL do they use the forms in correspondence with patterns of event construal in the target language? We are interested in the factors that determine creative language use in L2s, adding to earlier studies on frequency effects by looking into unscripted language production. The analyses are therefore based on data from speakers of different languages who were asked to carry out the same verbal task. ${ }^{5}$ Given our findings in previous studies (cf. Carroll et al., 2012; Flecken et al., 2015b; Gerwien \& Stutterheim, 2018; Stutterheim et al., 2020) the following three languages were selected: French, German, and English, with two groups of learner-language speakers with French as L1 and German and English as L2s.

\subsection{SELECTION OF LANGUAGES}

The languages selected in this study represent different patterns in event construal in spatial-typological terms: in French, spatially relevant features of the figure in motion form the core of the concepts used to describe directed motion; in English and German, speakers follow a different pattern in that concepts based on features of the ground traversed by the figure in motion are critical in motion event construal. Thus, one and the same situation will be described as un homme marche dans la rue 'a man walks in the street' or a man is walking down a street or ein Mann geht eine Straße entlang 'a man goes a street along'. There is a further contrast, in this case between German and English, with respect to the verbal inventory. While the German lexicon offers a rich repertoire of manner verbs expressing locomotion with only a few path verbs,

[5] The data analysed were elicited in the context of an earlier study (cf. Carroll et al., 2012). In this previous analysis part of the data elicited was not used, which means that the numbers differ in the present case. 
the English lexicon has a number of path verbs of Romance origin (e.g., to approach, to enter, to advance) in addition to the Germanic manner verbs. Given the option for use of the verbs to walk in versus to enter for example, English native speakers may, however, show preference for the Germanic manner verb (cf. Stefanowitsch, 2013).

Differences and similarities at this level formed the basis in selecting the L1 and L2 groups. L1 French learners of English and German have to acquire new forms and - with these forms - different criteria for event construal in the context of language use. Instead of varying the factor L2 with respect to typological features in the domain of spatial relations, as in numerous previous studies (Cadierno \& Ruiz, 2006), variation in the present case is within one type - satellite-framed languages - with the control factor given by the L1. Both groups of learners share the same criteria for event construal given the task. They acquire languages, which, in addition to new forms, require the construction of novel patterns of conceptualisation. The relevant contrast between German and English, as the L2, lies in the repertoire of verbs, given the distribution between manner and path verbs. L1 speakers of French can select verbs in L2 English that fit their L1 frame, which is not the case for German. This specific combination of languages allows us to address questions on the stability of L1-based conceptual framing as well as factors related to the selection and use of lexical items that correspond to these frames, despite infrequent use in the TL.

\subsection{STUDY DESIGN}

\subsubsection{Participants}

The L1 speakers were all students (aged between 19 and 30) without advanced knowledge of any other language. The L1 English speakers were participants in a summer school at the University of Heidelberg, all with very little knowledge of German. Recordings in English were carried out during the first days of their stay, and the experiment was conducted in English by a native speaker. The L1 German and L1 French speakers were students at the University of Heidelberg and the University of Paris VIII, respectively, and the recordings were conducted in each case by a native speaker at the participants' home institution. Participants with advanced knowledge of a second language were excluded from the experiments.

Two groups of L2 speakers were recruited, both with French as L1 and English ( $n=19$ age 21 to 32$)$ and German $(n=20$, age 19 to 28$)$ as their L2, respectively. All L2 speakers were given a questionnaire on their linguistic as well as social background. The homogeneity of the groups in terms of L2 competence was ensured based on formal language tests (a re-narration test in 
the case of the English L2 group, a C1 language certificate (C1 of the European Frame of Reference) in the case of the German L2 group). Knowledge of a third language was stated as limited by this group. All French learners of English started learning English at school after the age of ten. English was also studied at university level and used later on a daily basis as professionals, either as teachers (second and third level), translators (English to French), or in their professions (export, marketing). All had spent several periods of time in an English-speaking country. In their re-narrations, the learners showed no formal errors, and lexical proficiency was high, but aspects of information structure (e.g., topic management; temporal frames) did not fully match the patterns found for this task in L1 English. All L1 French-L2 German learners also started learning German after the age of ten and were university students studying German when recorded. Recordings were carried out while participating in a German language course for advanced learners at the Heidelberg University. For admission to the Faculty of Modern Languages in the German department, students have to have a C1-certificate. All subjects indicated some knowledge of English. All L2 subjects had spent longer periods of time abroad where they used the L2 on a regular basis. The English L2 group was recorded at the University of Paris VIII and Paris X. The German L2 group was recorded at Heidelberg University.

\subsubsection{Stimuli}

The stimuli were short live-recorded video clips (6 sec) showing situations in which persons or vehicles move along a path with a more or less evident goal (Figure 1). The 13 critical clips were embedded in 44 filler items which covered events of different types: causatives, activities, states. The inter-stimulus interval was $8 \mathrm{sec}$ and showed a blank screen (see 'Appendix B' online for full set of stimuli <https://doi.org/10.11588/data/ZMWDP5>).

\subsubsection{Procedure}

Participants were recorded in university labs. They were seated in front of a monitor on which the stimuli were shown. The instruction given is as follows:
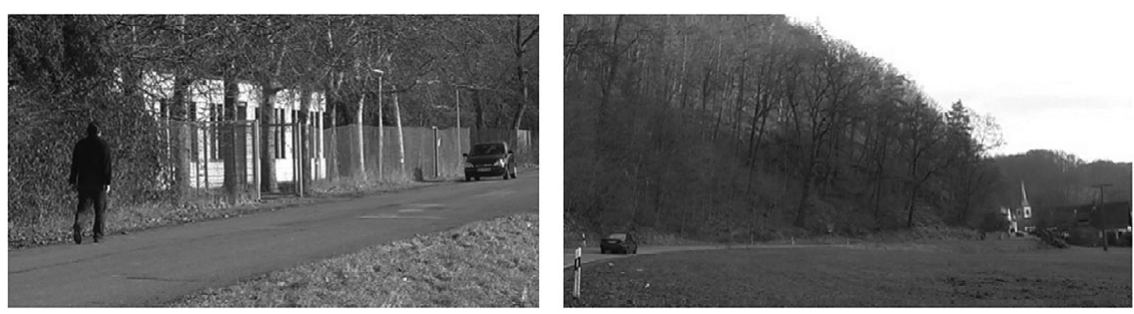

Fig. 1. Example stimuli. 
"You will see a set of video clips, 57 in all, showing everyday events which are not connected with one another. Each scene is preceded by a blank screen with a focus point. Your task is to tell what is happening and you may begin as soon as you recognize what is going on. It is not necessary to describe the scene in detail - just focus on what is happening. The task takes approximately 20 minutes" (see 'Appendix A' online for instructions in French and German $<$ https://doi.org/10.11588/data/ZMWWDP5>). The instruction was given in the language to be used in the experiment. Participants' spontaneous responses were audio-recorded.

\subsection{H Y P O THESES}

Previous research on the languages in the present study (Carroll et al., 2012; Flecken et al., 2015b; Gerwien \& Stutterheim, 2018) form the basis for the following hypotheses:

1. The groups of L1 speakers will differ with respect to the event frames selected in relation to event type: French L1 speakers draw on a dynamic frame with path verbs and directional adjuncts, or a stationary motion frame with manner verbs and locational adjuncts or zero adjuncts, depending on the features of the situation. German and English speakers will predominantly select dynamic event frames with manner verbs in combination with directional satellites.

2. The groups of L2 speakers will differ with respect to the event frames selected from the groups of native speakers of the TL. At the level of linguistic means, differences will concern use of satellites and combinations of verbs and satellites. Patterns will align more with those observed in the L2 speakers' L1.

\subsection{ANALYSES}

\subsubsection{Coding categories}

The oral responses for the 13 critical clips were transcribed and inserted in a spreadsheet with the sentence as the unit of analysis. Transcriptions and coding were carried out by native speakers of the respective language and were checked by a second researcher. Coding was rather unproblematic given the categories applied for the analyses. The few cases where coders did not agree initially (mainly questions of segmentation) were submitted to a group of four researchers, who could resolve issues by discussion. The forms coded are verb type (manner/path/other), prepositional phrases as spatial adjuncts (location/ direction: a man is walking on/down the street), and verb particles (ein Mann geht die Straße entlang 'a man walks the street along'). All forms which provide 
spatial information outside the verb are termed S A T E L L I T E S and include noun phrases (a man is passing a building), prepositional phrases, and particles. ${ }^{6}$ Statistical analyses were carried out for both formal and spatial semantic categories as well as their combinations (constructions of the type verb + satellite). The coding of verb types and satellite types in each language also allowed us to evaluate an additional factor: the diversity of lexical items used. We consider lexical diversity as an approximation of the consistency of the L1 speakers' output (adding to sheer frequency of occurrence), as well as an indicator for the ability of L2 speakers to mirror the diversity found in their TL.

\subsubsection{Statistical analyses}

In order to assess the statistical reliability of the contrasts between the language groups, as observed on the basis of counting specific occurrences, a number of statistical models was set up using the statistical software R, version 3.6.1 (R Core Team, 2019) as well as the packages 'lme4', version 1.1-21 (Bates, Maechler, Bolker, \& Walker, 2015), 'car', version 3.0-7 (Fox \& Weisberg, 2019), and 'multcomp', version 1.4-10 (Hothorn, Bretz, \& Westfall, 2008). The majority of the analyses were carried out with random-effects binomial logistic regression models. In these models the response variable of interest was binary coded (e.g., use of a manner of motion verb or use of a satellite encoding location: yes $=1$, no $=$ 0). The only fixed factor in all models was L A N G U A G E G R O U P with five levels. In addition, random intercepts were included for both the random variable "participant" as well as "item". A main effect of the predictor language group was consistently calculated using sums of squares (Type II) with the 'Anova' function from the 'car' package. Relevant pairwise comparisons were retrieved from the original model using the 'glht' function from the 'multcomp'-package. Since there are specific theory-based predictions for all relevant comparisons, alpha level adjustments were not required (O'Keefe, 2003). To improve readability, indications of statistical significance were included in all figures below. Details on model specifications, full model outputs, and relevant comparisons can be found in 'Appendix C' (online <https://doi.org/10.11588/data/ZMWDP5>).

\subsection{RESULTS}

The initial analyses compared the frequency of semantic verb types (model 1 and 2 in 'Appendix C') and semantic satellite types (prepositional phrases and particles,

[6] Contrary to Talmy's (2000) original definition of the term satellite, which applies to particles and morphological means such as prefixes with a spatial meaning, the term has since been extended to also cover syntactic forms of adjuncts which encode information on ground and direction (cf. Beavers et al., 2010). 


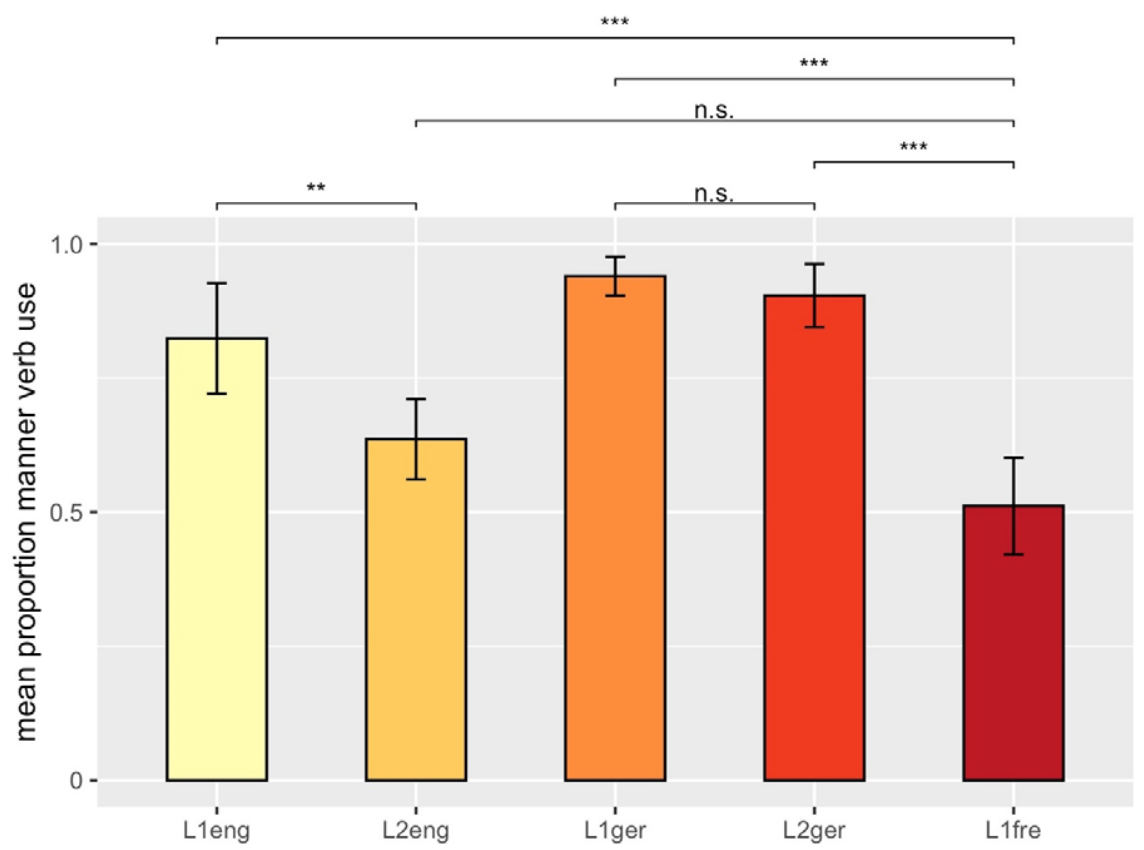

Fig. 2 Frequency of manner verbs (the graph shows by-subjects aggregated data; error bars indicate $95 \%$ confidence intervals).

model 3 and 4 in 'Appendix C') across the five groups (L1 French, L1 English, L1 German, and the L2s German, English). Figure 2 and Figure 3 show results for the use of manner and path verbs in describing the stimuli across language groups, as well as the results of the relevant pairwise comparisons. Figure 4 and Figure 5 show the results for the two different types of spatial satellites (location/direction). All four models showed a main effect of L AN G UAGE GRO U P.

Next, we compared frequency of use of constructions. We distinguish two types of constructions: manner verbs with a directional satellite (Figure 6, model 5 in 'Appendix C') and manner verbs with a locational satellite (Figure 7, model 6 in 'Appendix C'). If a manner verb was combined with more than one locational or directional element it was taken as one datapoint. ${ }^{7}$ Both models showed a main effect of LANGUAGE GROUP. Constructions with both locational and directional satellites also occurred. However, despite numerical

[7] Example for two directional adjuncts: eine Dame läuft an einer Straße entlang auf eine Bushaltestelle zu (a lady walks on a street along towards a busstop); example for two locational adjuncts: une voiture roule sur une route déserte dans la campagne (a car drives on a deserted road in the countryside). 


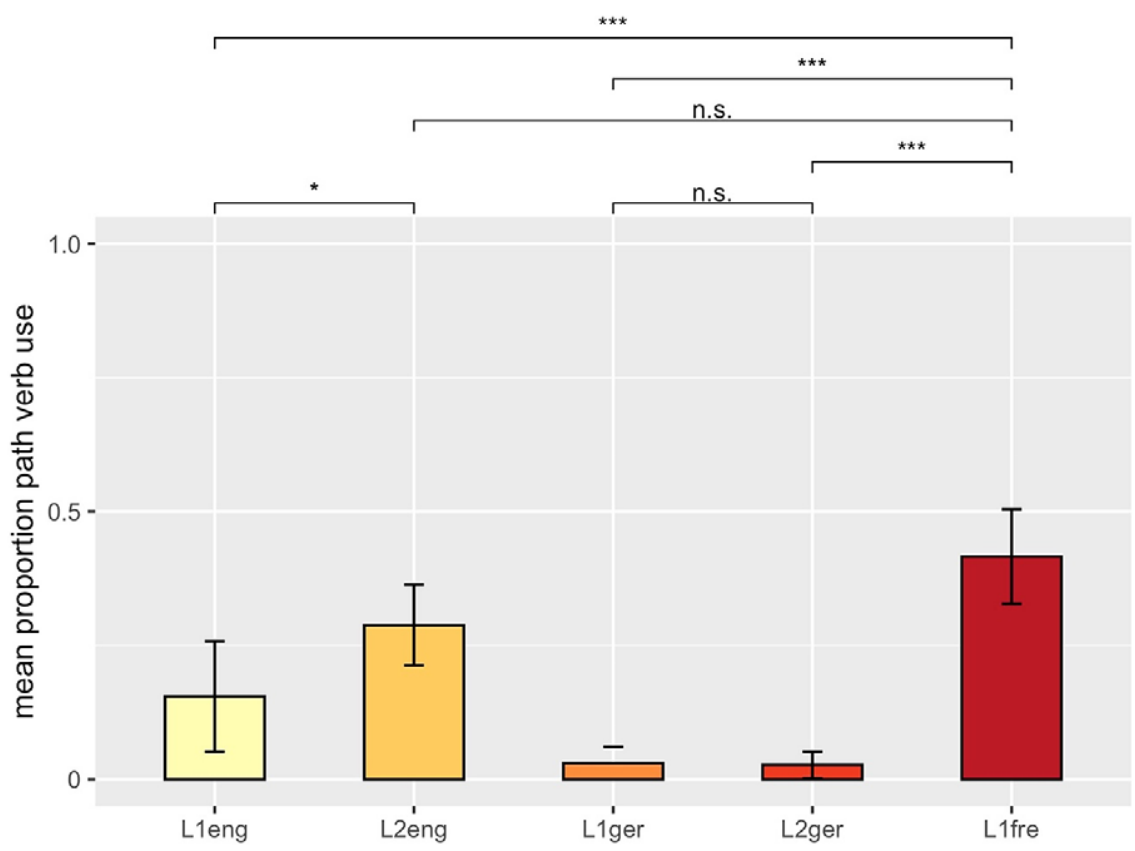

Fig. 3 Frequency of path verbs (by-subjects aggregated data; error bars indicate $95 \%$ confidence intervals).

differences, there was no statistically significant main effect of LANGUAGE GRO U P. This analysis is not reported here (but see model 7 in 'Appendix C').

Participants also produced utterances with a verb, but no adjunct (such as une femme marche 'a woman walks'). These zero-adjunct constructions occurred with the following frequency in the 5 language groups: $15 \%$ in French, 2\% in German, and 0\% in English; $11 \%$ in L2 German, and 5\% in L2 English (cf. discussion in Stutterheim et al., 2020).

A further set of analyses targeted lexical diversity across language groups (Figure 8), indicating the level of consistency in the selection of specific lexical items: verbs in representing the event type and satellites in expressing the type of spatial concept. Verb diversity was calculated by dividing the total number of unique verb types by the total number of verbs per language (analyses used overparticipants and over-item aggregated data; e.g., 6 unique / 13 total $=0.46$ ). Satellite diversity was calculated by dividing the total number of unique satellites by the total number of satellites (analyses used over-participants and overitems aggregated data). Note that statistical significance is only indicated in Figure 8 if both types of aggregation yielded consistent results (models $8 \mathrm{~A}, 8 \mathrm{~B}$, and 9A, 9B in 'Appendix C'). There was a main effect of L AN G U A G E G R O U P in the verb diversity analyses, but not in the satellite diversity analyses. 


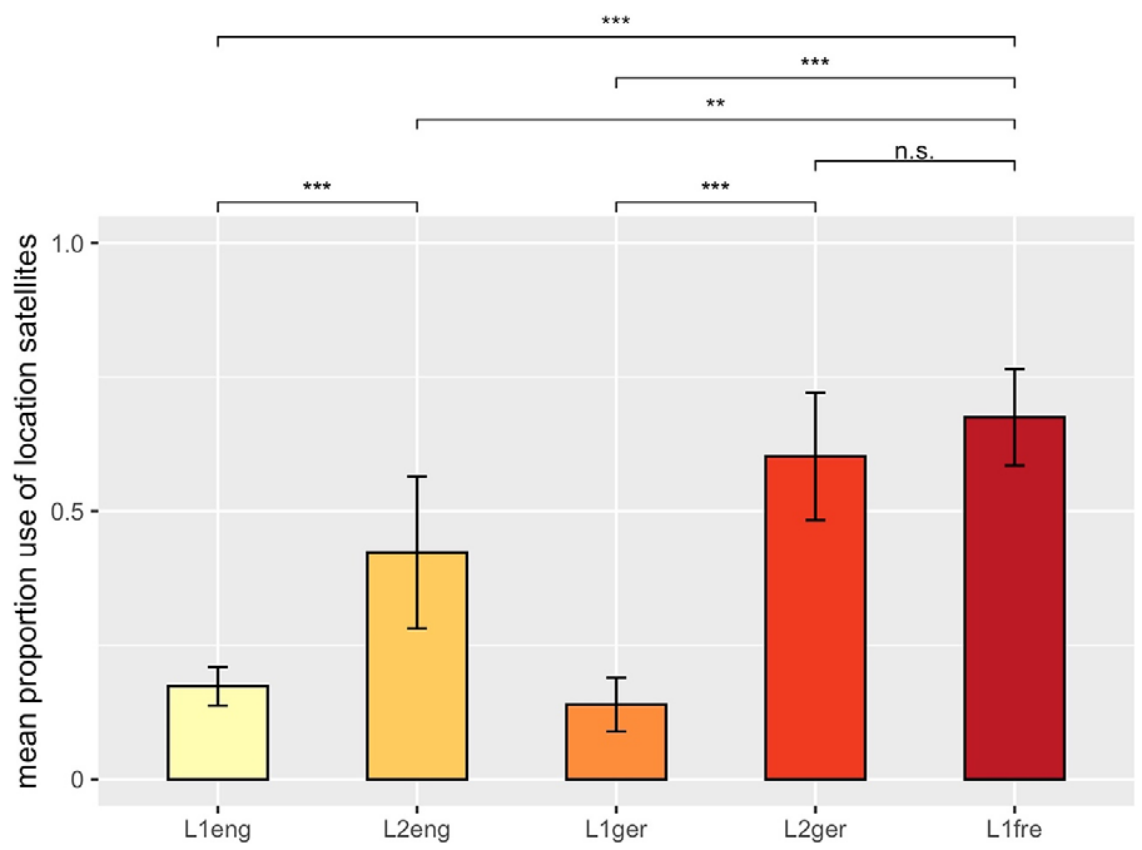

Fig. 4 Frequency of satellites referring to location (the graph shows by-subjects aggregated data; error bars indicate $95 \%$ confidence intervals).

\section{Discussion of results}

\subsection{I GROUPS}

The statistical analyses confirm results of previous studies on the typological features of the three languages (Slobin, 2004; Pourcel \& Kopecka, 2005; Carroll et al., 2012; Muñoz \& Cadierno, 2019). There is a significant difference between speakers of English and German, on the one hand, and French speakers on the other hand, with respect to the relative number of manner and path verbs used. French speakers use a higher number of path verbs. Although French is a verb-framed language, French speakers use manner verbs at a rate of approximately $50 \%$ across all utterances. German speakers use manner verbs in almost $100 \%$ of all cases, while occurrences are lower for the English group. Analyses of the use of constructions confirm established contrasts in language-specific patterns of event construal for these languages: in French, directed motion events are expressed using path verbs with adjuncts providing further information on direction, quasi-exclusively in relation to a landmark or goal (vers ( $\mathrm{x}$ ) 'towards ( $\mathrm{x}$ )'). If events are construed on the basis of manner of motion, the event is typically expressed in terms of its location (une femme marche and une femme marche dans la rue 'a woman walks (in the street)'). 


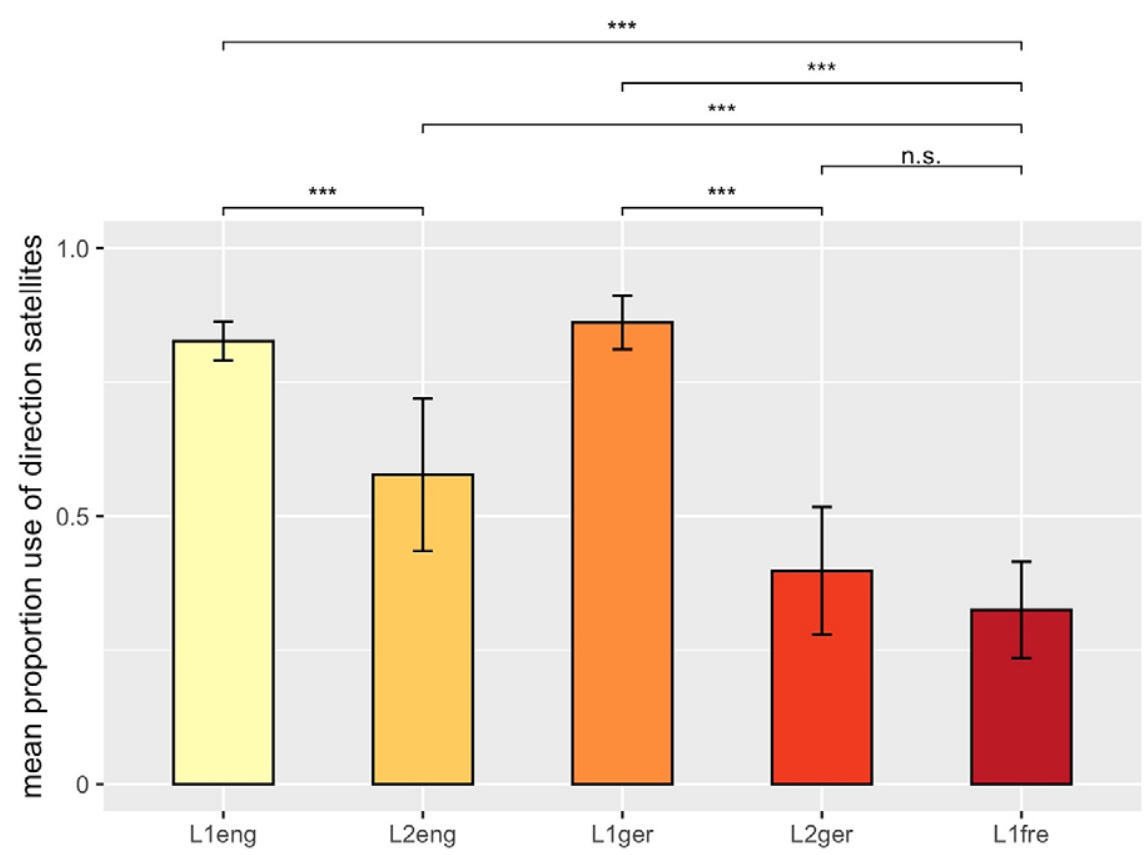

Fig. 5 Frequency of satellites referring to direction (the graph shows by-subjects aggregated data; error bars indicate $95 \%$ confidence intervals).

Information on the direction of the figure is only rarely provided (Figures 6 and 7).

We conclude that, in German and English, manner of motion is anchored in a different event frame in that satellites (prepositions / verb particles) encode directed motion related either to a landmark ( $z u$ 'to', to, towards) or to features of the ground (along, down) (see Figure 10, Figure 11, Figure 12). Figure 9 shows the frequency of occurrence of the event types with directional vs. locational spatial reference. In sum, the picture obtained in the data analysis confirms hypothesis 1 on the typological differences between the three languages.

Contrasts with respect to event construal appear at the level of the lexical items used to express the events depicted in the scenes (Figure 8). French speakers use a significantly wider range of verb types compared to the other groups, a finding that is grounded in the results for the frequency with which manner and path verb are used (Figure 2, Figure 3). This means that the forms used by German and English speakers are more consistent. Significantly, this homogeneity can be viewed as an indicator of the input which learners of the respective language encounter. The picture differs, however, for the satellites. 


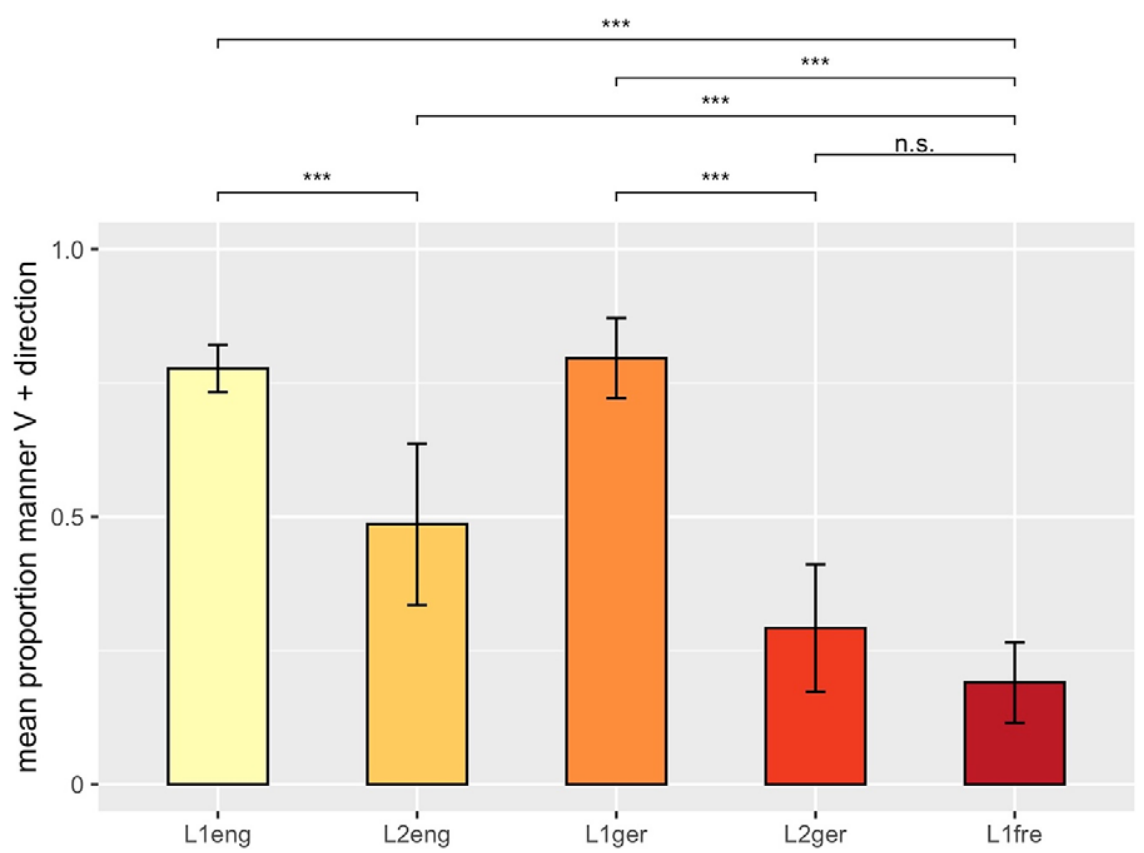

Fig. 6 Frequency of constructions with a manner verb and a directional satellite (the graph shows by-subjects aggregated data; error bars indicate $95 \%$ confidence intervals).

While diversity in general does not differ significantly between groups (Figure 8), diversity of specific types (direction/location) does (Figure 4 and Figure 5, and Figure 10 and Figure 11). L1 French speakers use a wide repertoire of prepositions which refer to the overall location, in contrast to the German and English speakers who use a wide range of prepositions to express differences in direction.

\subsection{2 GROUPS}

The task for the French learners of both Germanic languages involves two components: acquisition of the respective lexical items with their syntactic properties, and acquisition of the associated principles in event construal which form the basis for the use of the constructions (verb + satellite) in the relevant contexts. Significantly for the learning process, the learners have to uncover the conceptual frame that underlies the use of these forms in the input: in English and German reference to manner of motion constitutes a core factor in event construal. This functions in combination with a range of specific forms and associated concepts that express differences in direction. This stands in 


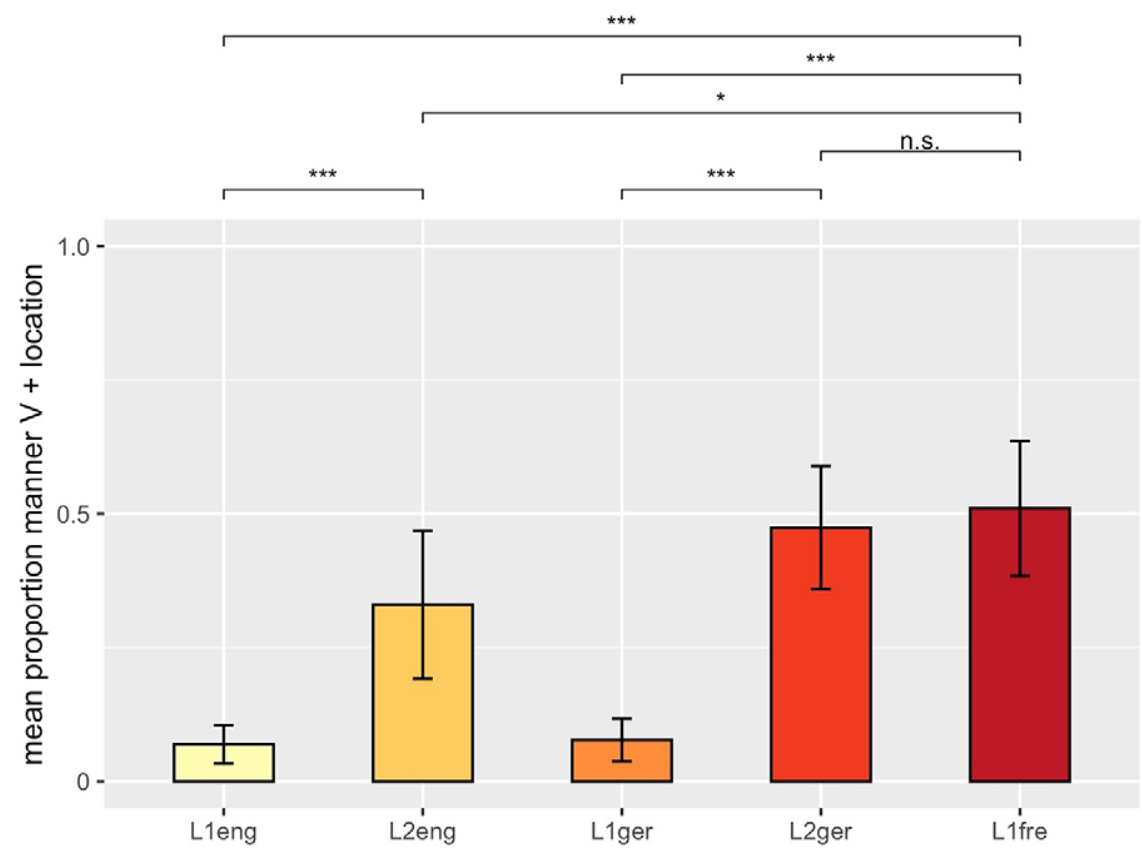

Fig. 7 Frequency of constructions with a manner verb and locational satellite (the graph shows by-subjects aggregated data; error bars indicate $95 \%$ confidence intervals).

sharp contrast with the pattern in French where the selection of manner of motion typically activates an event frame based on non-directed motion in that it focuses location only, given the fact that means to express direction are encoded via the verb.

The two groups of advanced learners of English and German mainly use manner verbs. However, in contrast to the TL speakers, they combine manner verbs with locational adjuncts to an extent not evidenced in the TL.

There are also differences between the two L2 groups. A significant difference lies in the number of path verbs used (Figure 3). L2 English speakers employ more path verbs than L2 German speakers, and even more than TL English speakers. At this level in the analysis, it seems as if the L2 English speakers were more successful in uncovering the pattern underlying event construal in the TL compared to the L2 German speakers. The number of verbalisations encoding directed motion is higher when compared to the L2 German speakers. However, a closer look at the data shows that the L2 speakers of English use path verbs in combination with adjuncts of the type 'direction of figure towards goal'. Encodings of direction, based on specific features of the ground (down, along, entlang 'along'), however, are practically absent in L2 

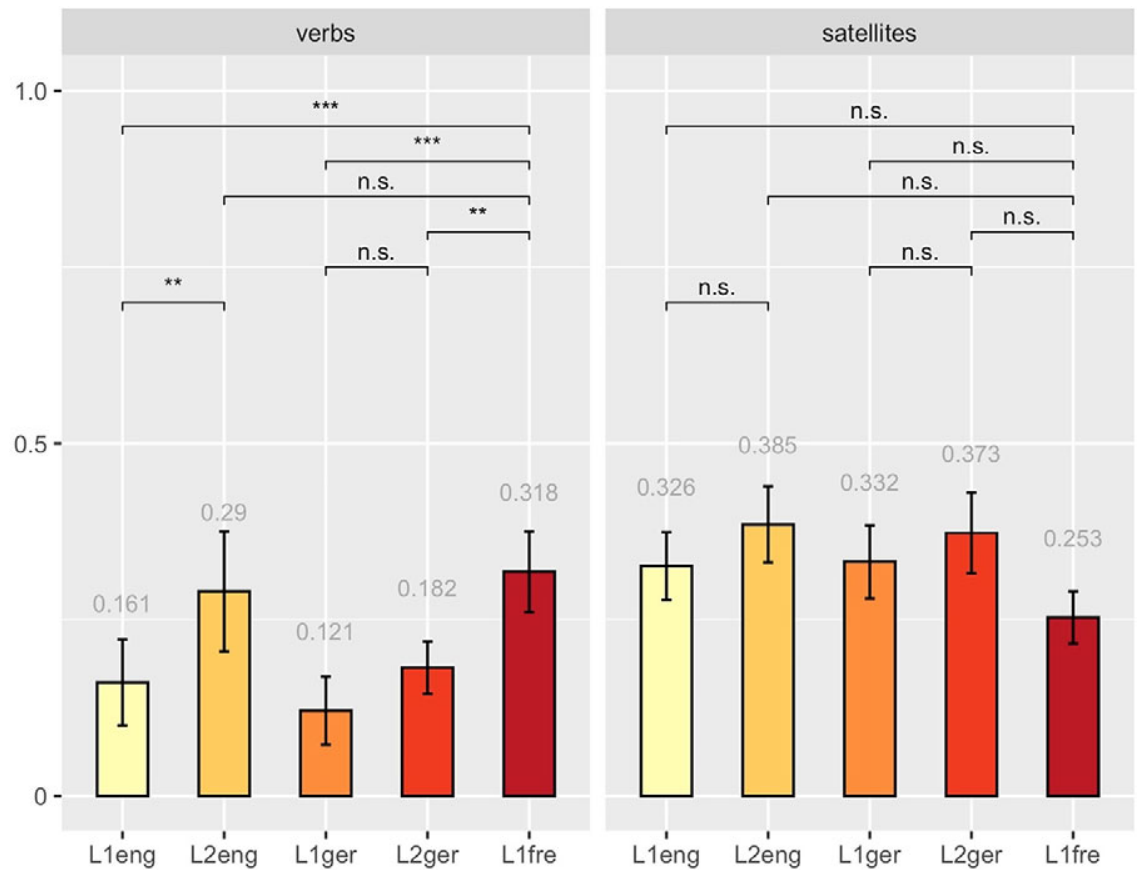

Fig. 8 Diversity of lexical items used; left: verb diversity; right: satellite diversity (the graph shows by-subjects aggregated data; error bars indicate $95 \%$ confidence intervals).

English as well as L2 German. Therefore, the findings for the L2 speakers correspond largely to the patterns in L1 French at the level of event construal. This confirms hypothesis 2 .

\subsection{THE FACTOR FREQUENCY}

In interpreting the role of frequency in the input, and its role in acquisition in the present context, a number of factors have to be put in place. Starting with the verbs expressing manner of motion, the learners have acquired the verbs that are frequent in the TL, and they use them. In German, manner verbs are more or less the only option, and the L2 speakers acquire and use them accordingly. ${ }^{8}$ However, L2 speakers of English differ from the TL speakers

[8] The manner of motion types shown in the video clips are of an unmarked type: walk and drive ('gehen' und 'fahren'). The frequency of these verbs in large corpora has not been separately controlled. We refer to studies by Fagard et al., 2013, Capelle, 2012, DWdS for German, which document the general frequency of these verbs in English and in German, respectively. 


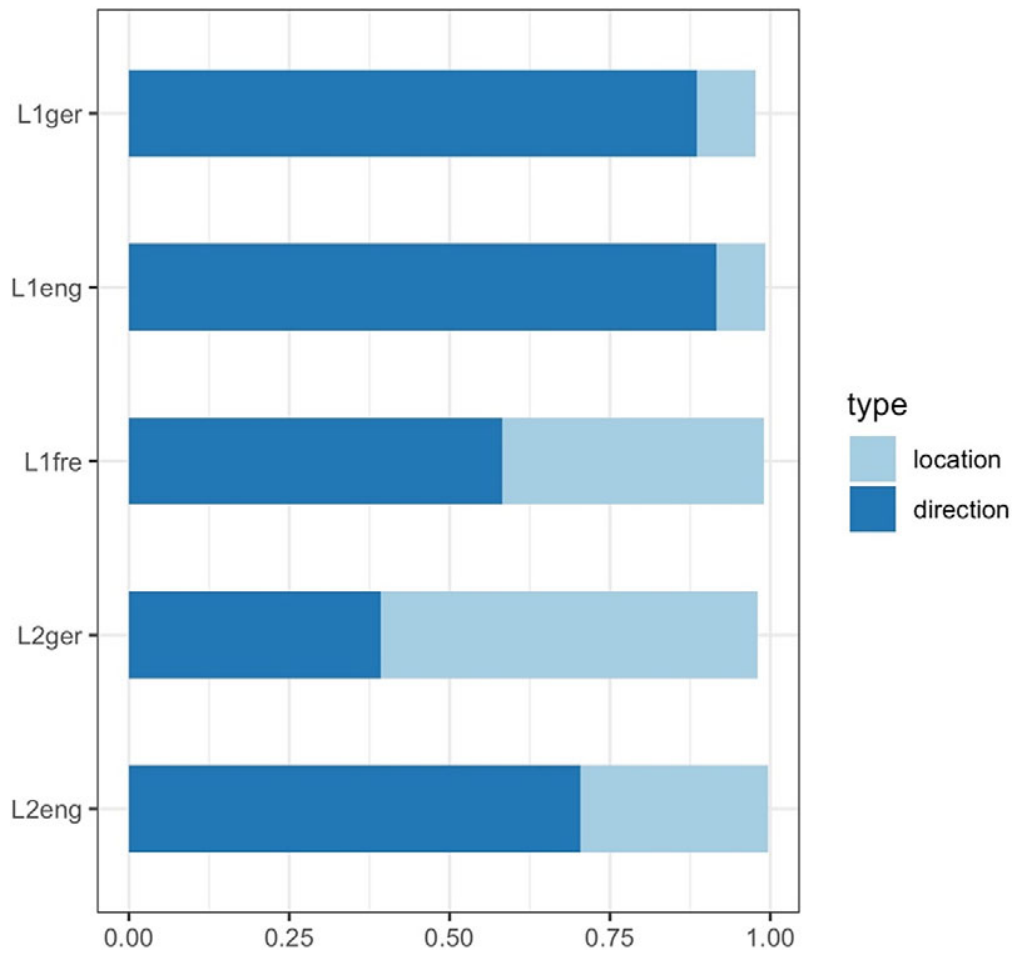

Fig. 9 Ratio of directional versus locational event framings (total number of each type / total number of utterances).

in that the L2 speakers use a significantly higher number of path verbs in the given corpus. Significantly, the frequency of these verbs in the input does not correspond to the frequency in the L2.

Furthermore, in the case of forms encoding spatial relations, the most frequent lexical item in the L1 German descriptions when encoding directional information is the verb particle entlang 'along' (Figure 12). This form, however, is rarely used by the L2 speakers. The same holds for down in L2 English, although this form is highly frequent in the L1. A closer look at all satellite forms used by the five groups clearly shows that the frequency of forms with respect to tokens, as well as semantic types, differs substantially for the TL native speakers and L2 speakers (see Figure 10 and Figure 11).

The results clearly show that L2 speakers do not construe and express motion events according to the patterns which are highly frequent in the TL data. The findings do not confirm a position which takes frequency of 


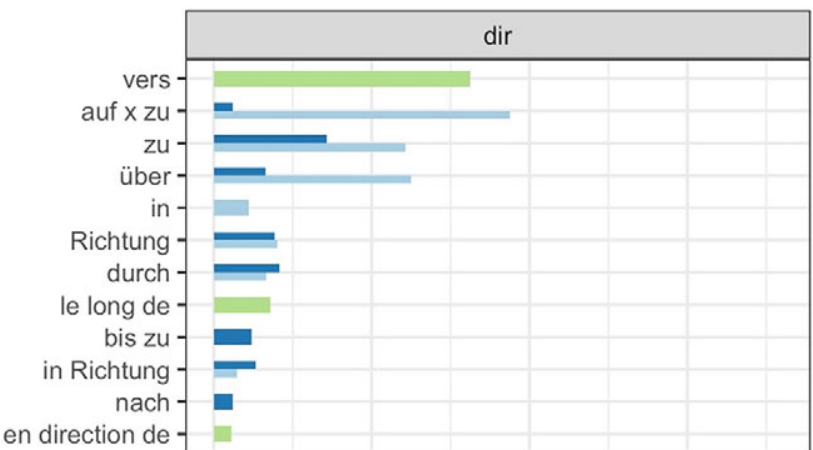

Language

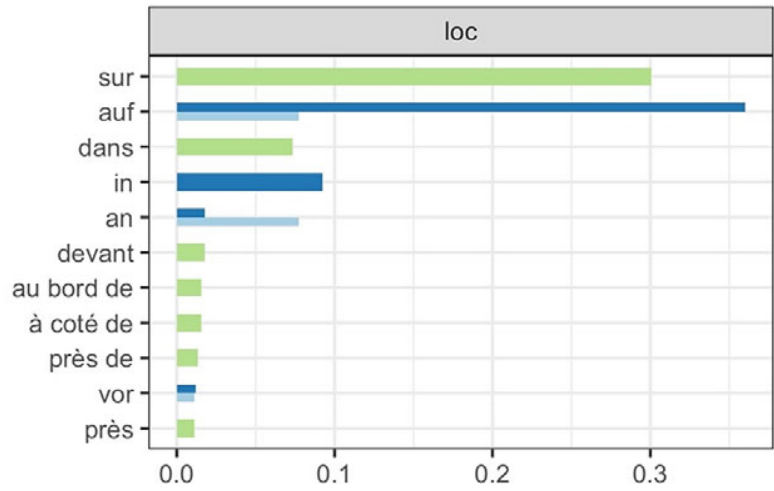

L1ger

L2ger

L1fre

Fig. 10 Distribution of prepositions in L1/L2 German and L1 French (type frequency / total number of prepositions).

occurrence and repetition as the major driving force for L2 comprehension and production (Ellis et al., 2008). If this assumption were correct, the learners of German and English, who are at a very advanced stage, should have acquired the TL pattern where manner verbs combine with forms expressing direction in highly specific terms (particles/prepositions).

The findings bring into focus a basic problem which has been pointed out in Section 2.4. Studies in the framework of usage-based theories on L2 acquisition view acquisition as successful once the forms or constructions have been stored in memory. Although in Wulff and Ellis (2018) the authors formulate a statement which at first sight would seem to be in accordance with the present conclusions - "Since everything is filtered through the lens of the L1, not all of the relevant input is in fact taken advantage of" (2018, p. 50) - there is an important difference to the position advocated in the present paper. Their 
VON STUTTERHEIM ET AL.

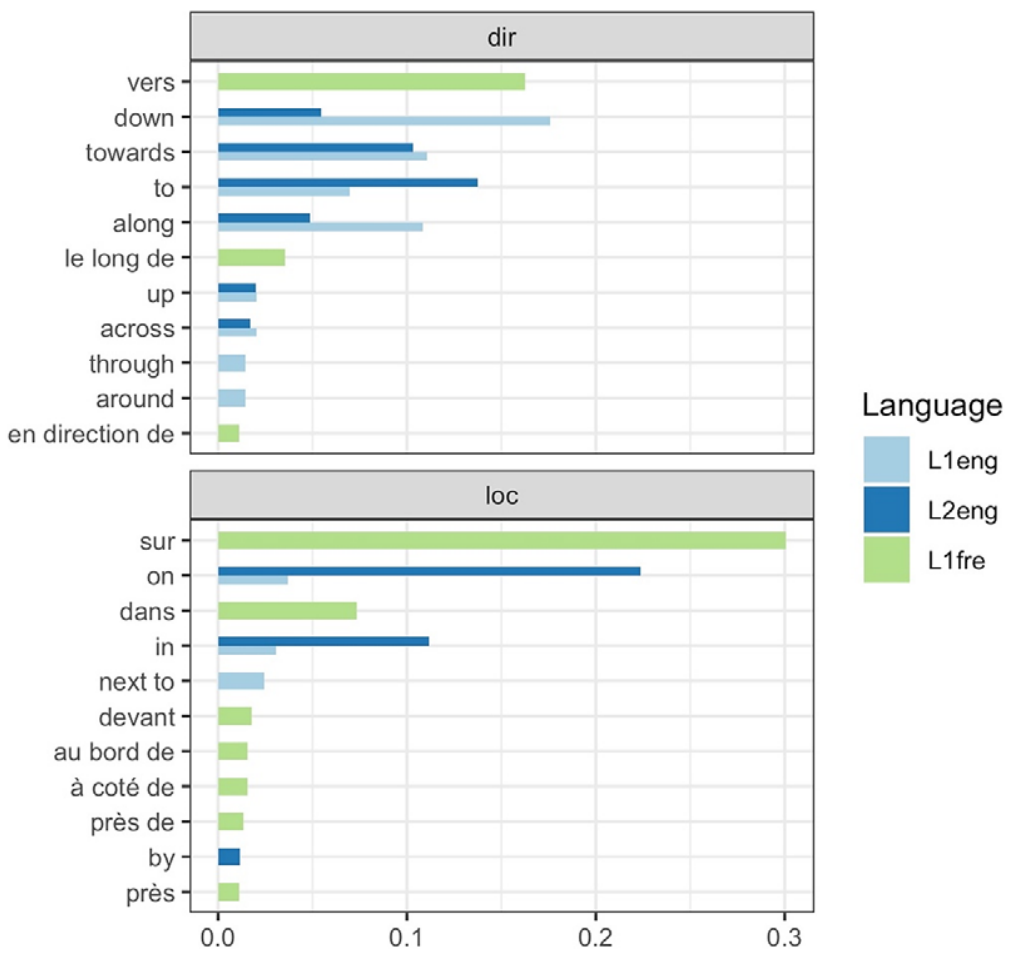

Fig. 11 Distribution of prepositions in L1/L2 English and L1 French (type frequency / total number of prepositions).

analyses do not target the question of adequate use, i.e., the acquisition of the range of factors in event construal which underlie language use in context. The factors viewed as relevant for L2 intake are saliency, contingency, and learned attention allocation (2018, p. 43). The impact of these factors, however, is identified at the form level only.

The present results point to the fact that the acquisition of L 2 forms is no more than an initial step. The acquisition of the underlying principles when conceptualising content for expression, which provides the basis for the use of these forms, constitutes the crucial second step. Significantly, the initial step does not necessarily lead to the second level of acquisition. The generalisation that L2 learning "follows statistical learning mechanisms" (Wulff \& Ellis, 2018, p. 39) as the central explanatory factor in L2 acquisition does not give due recognition to the complexity of the task that the L2 learner faces. 


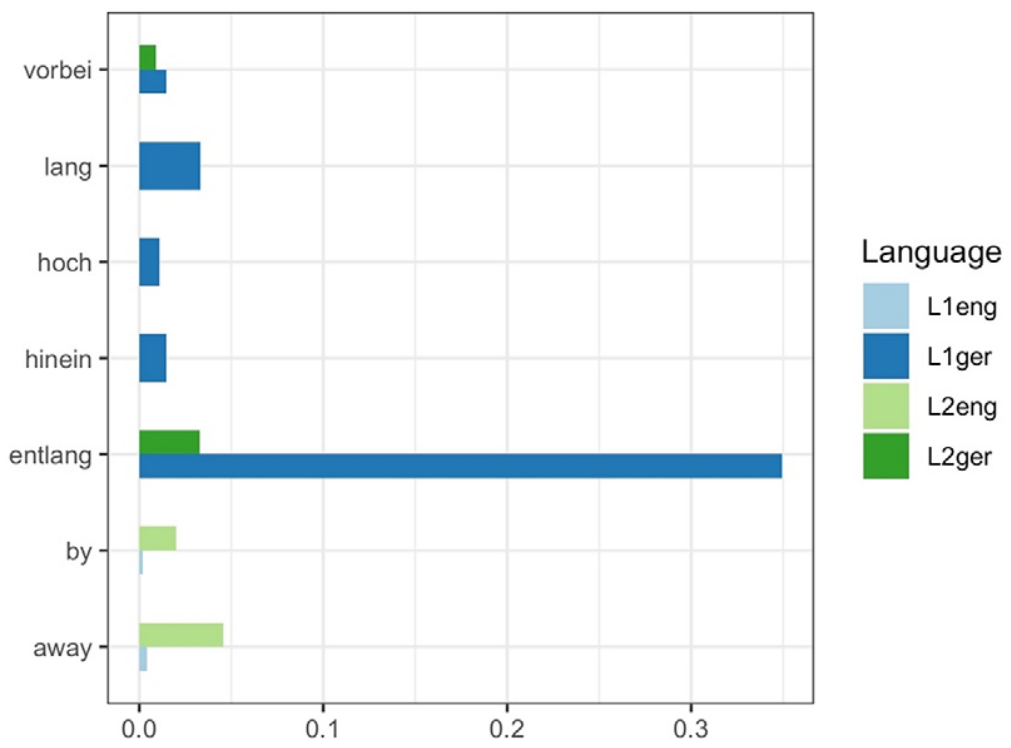

Fig. 12 Particles across language groups (type frequency / total number of particles).

\section{Conclusion}

In the present study verbalisations by L1 speakers were compared with those of $\mathrm{L} 2$ speakers when conveying information on the same set of motion events. Despite the fact that the L2 speakers are at very advanced proficiency levels with adequate exposure to the L2s in terms of the frequency with which they would have encountered references to motion events, the contrasts regarding the roles which the basic concepts serve in motion event construal across the two languages reveal the deep-seated ramifications at issue in language acquisition. The L2 speakers' responses to the stimuli differ markedly from those of TL speakers, both at the level of event construal and with respect to the types of constructions used, while correspondences are confined to the level of specific lexical verbs. The L2 speakers proceed in terms of fundamental features of their L1 which determine event construal, as well as in terms of the constructions and lexical means at the level of spatial function words (prepositions/ particles), despite the many years of exposure to the TL. The findings are not in accordance with the assumption that "it is the number of times the string appears in the input that determines fluency" (Ellis et al., 2008, p. 384), or as Littlemore (2009, p. 36) states: "Probabilistic processing can be seen as a kind of 'intuitive statistics'. In terms of construal, the argument here would be that 
learners gradually attune themselves to the construals preferred by the target language and match them to the situations in which they encounter them. They are thus able to use them appropriately without being fully aware of the fact that they are doing so." While it is indisputable that frequency plays an important role for language acquisition, it is precisely this level of language competence which is not automatically and unconsciously supported by frequency of input. The criteria which determine event construal are deeply rooted in any given linguistic system in the form of grammaticalised categories, as well as categories which are systematically represented in the lexicon. Research in the field of language and cognition (Slobin et al., 2010; Lupyan, 2016; for a review see Thierry, 2016) has shown how these factors shape the structure of the relevant knowledge base as well as the associated processes of conceptualisation. The problem for the language learner lies in the fact that these criteria are not represented in overt terms. Neither the verbs, nor the constructions as such, reveal this basic difference between German/English and French at the level of event construal for the learners.

In contrast to processes in L1 acquisition where cognitive structures are built up, and in line with linguistic experience, the L2 learner's knowledge at a conceptual level has to be recognised as a decisive precondition in the acquisitional process. This means that the role of frequency which has been found for L1 acquisition and which has been interpreted convincingly in the framework of a usage-based approach (Tomasello, 2006; for a discussion see Lieven, 2010) does not find a parallel in L2 acquisition and use. As the present results show, learners do not seem to "attune themselves to the construals preferred by the target language, and match them to the situations in which they encounter them" (see above, Littlemore, 2009, p. 36). In language production, the planning process starts with the conceptualisation of content for speaking. At this level, speakers draw on deeply entrenched conceptual structures which are triggered automatically in response to external stimuli or internal factors. When preparing to describe a motion event, L2 speakers activate the abstract schemata formed on the basis of their L1 - as our data show. These schemata function as 'pull factors' in the sense that they determine the requirements which have to be served by the L 2 linguistic material. This results in formally adequate but functionally infelicitous language use.

Note that our findings have implications with regard to the current debate on language and cognition. If it were the case that every adult had basically the same conceptual representation of a situation, as claimed by universalists, then 'the mapping' (Jackendoff, 1990) onto the new language should not be affected by specific features in the L1. The present results show how the relevant cognitive processes are structured by the L1, and more specifically by the event frames which transcend the L1 (cf. the notion of conceptual transfer 
overview in Jarvis \& Pavlenko, 2008; Pavlenko, 2011; Sharpen, 2016; Munoz \& Cadierno, 2019 ${ }^{9}$ ).

When confronted with a verbal task, speakers can draw on all resources which are useful in solving the task. L2 speakers follow the pathway from conceptualisation to formulation just as L1 speakers. The first step involves the activation of an event frame in response to the visual input. For a speaker of French this means that two frames may be potentially activated: the directed motion event frame, with a figure-related spatial concept of motion towards a goal, or the 'stationary' motion event frame focusing on the overall location, depending on specific features of the situation at the level of goal-oriented directionality (Gerwien \& Stutterheim, 2018). This differs significantly from L1 German and English, where two frames involving direction are activated depending on a potential goal: directed motion based on contours of the ground and goal-directed motion. Despite their advanced proficiency, the L2 speakers in the present study have not acquired the TL patterns in event framing. Moreover, the two groups show language-specific patterns. In German, manner verbs are more or less the only option available for expressing motion events. L2 learners pick up these verbs, but for the L2 speakers with French L1 these verbs activate the 'stationary' motion event frame in the majority of cases. The English L2 speakers, by contrast, use more path verbs, probably supported by the corresponding forms in their L1, since the L2 forms show a Romance origin. But note that, although the L2 speakers of English use manner verbs with directional spatial concepts, they still proceed on the basis of the L1 patterns in that they follow a figure-based framing and not a groundbased framing as required in the TL. This leads us to the conclusion that, in acquiring the lexical means for the expression of motion events, the learners have not 'cut' the link to the highly abstract event frames established in the course of L1 acquisition.

Our results point to the extent to which conceptual framing may outweigh frequency as a factor in L2 acquisition. Since there are no formal indicators for this abstract level of knowledge in the input, even the high frequency of a specific pattern in the input does not help the learner. It would be important to include this crucial component of linguistic knowledge in formal language teaching.

[9] Interestingly, this study on English learners of Spanish on the expression of motion events shows results very much in line with the present study. However, the interpretation takes a different position. The patterns are viewed in terms of lexicalisation patterns which constrain the combination of atelic verbs with path adjuncts in Spanish. The fact that the L2 speakers follow basically L1 patterns in their verbalisations are interpreted as transfer phenomenon at this level (Munoz \& Cadierno, 2019). By contrast, we claim that the basis for these patterns lies in the tight alliance between conceptual and linguistic structures. 


\section{REFEREN C ES}

Arnon, I. \& Snider, N. (2010). More than words: frequency effects for multi-word phrases. Fournal of Memory and Language 62(1), 67-82.

Bates, D., Maechler, M., Bolker, B. \& Walker, S. (2015). Fitting linear mixed-effects models using lme4. Fournal of Statistical Software 67(1), 1-48.

Beavers, J., Levin, B. \& Shiao W. T. (2010). The typology of motion expressions revisited. Fournal of Linguistics 46(2), 331-377.

Berthele, R. (2013). Disentangling manner and path: evidence from varieties of German and Romance. In J. Goschler \& A. Stefanowitsch (eds), Variation and change in the encoding of motion events (pp. 55-75). Amsterdam: John Benjamins.

Bley-Vroman, R. (2002). Frequency in production, comprehension, and acquisition. Studies in Second Language Acquisition 24(2), 209-213.

Cadierno, T. \& Ruiz, L. (2006). Motion events in Spanish L2 acquisition. Annual Review of Cognitive Linguistics 4(1), 183-216.

Cappelle, B. (2012). English is less rich in manner-of-motion verbs when translated from French. Across Languages and Cultures 13(2),173-195.

Carroll, M. (2000). Representing path in language production in English and German. In C. Habel \& C. v. Stutterheim (eds), Räumliche Konzepte und sprachliche Strukturen (pp. 97-118). Tübingen: Niemeyer.

Carroll, M., Weimar, K., Flecken, M., Lambert, M. \& Stutterheim, C. v. (2012). Tracing trajectories: motion event construal by advanced L2 French-English and L2 FrenchGerman speakers. Language, Interaction and Acquisition 3(2), 202-230.

Conklin, K. \& Carroll, G. (2018). First language influence on the processing of formulaic language in a second language. In A. Siyanova-Chanturia \& A. Pellicer-Sanchez (eds), Understanding formulaic language: a second language perspective (pp. 62-77). New York: Routledge.

Croft, W. \& Cruse, A. (2004). Cognitive Linguistics. Cambridge: Cambridge University Press.

Durst-Anderson, P., Smith, V. \& Nedergaard Thomsen., O. (2013). Towards a cognitivesemiotic typology of motion verbs. In C. Paradis, J/. Hudson \& U. Magnusson (eds), The construal of spatial meaning (pp. 118-143). Oxford: Oxford University Press.

DWDS - Digitales Wörterbuch der deutschen Sprache. Das Wortauskunftssystem zur deutschen Sprache in Geschichte und Gegenwart. Berlin-Brandenburgischen Akademie der Wissenschaften (eds). Online <https://www.dwds.de/>.

Ellis, N. C. (2002). Frequency effects in language processing. Studies in Second Language Acquisition 24(2), 143-188. https://doi.org/10.1017/S0272263102002024

Ellis, N. C. (2003). Constructions, chunking, and connectionism: the emergence of second language structure. In C. Doughty \& M. H. Long (eds), Handbook of second language acquisition (pp. 63-103). Oxford: Blackwell.

Ellis, N. C. (2013). Construction grammar and second language acquisition. Oxford: Oxford University Press.

Ellis, N. C., Frey, E. \& Jalkanen, I. (2009). The psycholinguistic reality of collocation and semantic prosody: lexical access. In U. Römer \& R. Schulze (eds.), Exploring the lexisgrammar interface (pp. 89-114). Amsterdam: John Benjamins.

Ellis, N. C., Simpson-Vlach, R. \& Maynard, C. (2008). Formulaic language in native and second-language speakers: psycholinguistics, corpus linguistics and TESOL. TESOL Quarterly 41(3), 375-396.

Ellis, N. C., Simpson-Vlach, R., Römer, U., Brook O’Donnell, M. \& Wulff, S. (2015). Learner corpora and formulaic language in second language acquisition. In S. Granger, G. Gilquin \& F. Meunier (eds), Cambridge handbook of learner corpus research (pp. 357-378). Cambridge: Cambridge University Press.

Erman, B. \& Warren, B. (2000). The idiom principle and the open choice principle. Text E Talk 20(1), 29-62.

Fagard, B., Zlatev, J., Kopecka, A., Cerruti, M. \& Blomberg, J. (2013). The expression of motion events: a quantitative study of six typologically varied languages. Annual Meeting of the Berkeley Linguistics Society 39(1), 364-379. 
Flecken, M., Athanasopoulos, P., Kuipers, J. R. \& Thierry, G. (2015a). On the road to somewhere: brain potentials reflect language effects on motion event perception. Cognition 141, 41-51.

Flecken, M., Carroll, M., Weimar, K. \& Stutterheim, C. v. (2015b). Driving along the road or heading for the village? Conceptual differences underlying motion event encoding in French, German, and French-German L2 users. Modern Language Fournal 99(S1), 100-122.

Flecken, M., Stutterheim, C. v. \& Carroll, M. (2014). Grammatical aspect influences motion event perception: evidence from a cross-linguistic, non-verbal recognition task. Language and Cognition 6(1), 45-78.

Fillmore, C. (1977). Scenes-and-frames semantics. In A. Zambolli (ed.), Linguistic structure processing (pp. 55-82). Amsterdam: North Holland Publishing Company.

Fox, J. \& Weisberg, S. (2019). An $\{R\}$ companion to applied regression, 3rd edn. Thousand Oaks, CA: Sage.

Gass, S. \& Mackey, A. (2002). Frequency effects and second language acquisition: A complex picture? Studies in Second Language Acquisition 24(2), 249-260.

Gerwien, J. \& Stutterheim, C. v. (2018). Event segmentation: cross-linguistic differences in verbal and non-verbal tasks. Cognition 180, 225-237.

Gries, S. \& Divjak D. (eds) (2012). Frequency effects in language learning and processing. Berlin: De Gruyter Mouton.

Goldberg, A. E. (2006) Constructions at work: the nature of generalization in language. Oxford: Oxford University Press.

Hernández, M., Costa, A. \& Arnon, I. (2016). More than words: multiword frequency effects in non-native speakers. Language, Cognition and Neuroscience 31(6), 785-800.

Hothorn, T., Bretz, F. \& Westfall, P. (2008). Simultaneous inference in general parametric models. Biometrical fournal 50(3), 346-363.

Jackendoff, R. (1990). Semantic structures. Cambridge, MA: MIT Press.

Jarvis, S. (2002). Topic continuity in L2 English article use. Studies in Second Language Acquisition 24(3), 387-418.

Jarvis, S. \& Pavlenko, A. (2008). Crosslinguistic influence in language and cognition. New York: Routledge.

Jiang, N. A. N. \& Nekrasova, T. M. (2007). The processing of formulaic sequences by second language speakers. Modern Language Fournal 91(3), 433-445.

Kartal, G. \& Sarigul, E. (2017). Frequency effects in second language acquisition: an annotated survey. Fournal of Education and Training Studies 5(6), 1-8.

Langacker, R. (1987). Foundations of cognitive grammar. Stanford, CA: Stanford University Press.

Larsen-Freeman, D. (1976). An explanation for the morpheme acquisition order of second language learners. Language Learning 26(1), 125-134.

Larsen-Freeman S. (2002). Making sense of frequency. Studies in Second Language Acquisition 24(2), 275-285.

Lieven, E. (2010). Input and first language acquisition: evaluating the role of frequency. Lingua 120(11), 2546-2556.

Littlemore, J. (2009). Applying cognitive linguistics to second language learning and teaching. Basingstoke: Palgrave Macmillan.

Lupyan, G. (2016). The centrality of language in human cognition. Language Learning 66(3), 516-553.

McDonald, S. A. \& Shillcock, R. C. (2003) Eye movements reveal on-line computation of lexical probabilities during reading. Psychological Science 14(6), 648-652.

Menn, L. \& Bastiaanse, R. (2016). Beyond Chomsky versus Skinner: frequency, language processing and aphasia. Aphasiology 30(11), 1169-1173.

Muñoz, M. \& Cadierno. T. (2019). Mr Bean exits the garage driving or does he drive out of the garage? Bidirectional transfer in the expression of path. International Review of Applied Linguistics in Language Teaching 57(1), 45-69.

O'Keefe, D. J. (2003). Colloquy: Should familywise alpha be adjusted? Against familywise alpha adjustment. Human Communication Research 29(3), 431-447. 
Pavlenko, A. (2011). Thinking and speaking in two languages. Bristol: Multilingual Matters.

Pourcel, S. \& Kopecka, A. (2005). Motion expression in French: typological diversity. Durham and Newcastle Working Papers in Linguistics 11, 139-153.

R Core Team (2019). R: a language and environment for statistical computing. R Foundation for Statistical Computing, Vienna, Austria. Online <https://www.R-project.org/>.

Robinson, P. (1995). Attention, memory, and the 'noticing' hypothesis. Language Learning 45 (2), 283-331.

Schachter, J. (1988). Second language acquisition and its relationship to Universal Grammar. Applied Linguistics 9(3), 219-235.

Sharpen, R. (2016). L1 conceptual transfer in the acquisition of L2 motion events in Spanish and English: the thinking-for-speaking hypothesis. Open Linguistics 1(2), 235-252.

Simpson-Vlach, R. \& Ellis, N. C. (2010). An Academic Formulas List (AFL). Applied Linguistics 31(4), 487-512.

Siyanova-Chanturia, A., Conklin, K. \& van Heuven, W. J. B. (2011). Seeing a phrase 'time and again' matters: the role of phrasal frequency in the processing of multi-word sequences. Fournal of Experimental Psychology: Language, Memory and Cognition 37(3), 776-84.

Siyanova-Chanturia, A. \& Pellicer-Sanchez, A. (eds) (2019). Understanding formulaic language : a second language perspective. New York : Routledge.

Siyanova-Chanturia, A. \& Spina, S. (2015). Investigation of native speaker and second language learner intuition of collocation frequency. Language Learning 65(3), 553-562.

Slobin, D. I. (1996). From thought and language to thinking for speaking. In J. Gumperz \& S. Levinson (eds), Rethinking linguistic relativity (pp. 70-96). Cambridge: Cambridge University Press.

Slobin, D. I. (2004). The many ways to search for a frog: linguistic typology and the expression of motion events. In S. Strömqvist \& L. Verhoeven (eds), Relating events in narrative. (pp. 219-257). Mahwah, NJ: Lawrence Erlbaum Associates.

Slobin, D. I., Bowerman, M., Brown, P., Eisenbeiß, S. \& Narasimhan, B. (2010). Putting things in places: developmental consequences of linguistic typology. In J. Bohnemeyer \& E. Pederson (eds), Event representation in language and cognition (pp. 134-165). New York: Cambridge University Press.

Stefanowitsch, A. (2013). Variation and change in English path verbs and constructions. In J. Goschler \& A. Stefanowitsch (eds) Variation and change in the encoding of motion events (pp. 223-243). Amsterdam: John Benjamins.

Stutterheim, C. v., Andermann, M., Carroll, M., Flecken, M. \& Schmiedtová, B. (2012). How grammaticized concepts shape event conceptualization in language production: insights from linguistic analysis, eye tracking data, and memory performance. Linguistics 50(4), 833-867.

Stutterheim, C. v., Gerwien, J., Bouhaous, A., Carroll, M., \& Lambert, M. (2020). What makes up a reportable event in a language? Motion events as an important test domain in linguistic typology. Linguistics 58(6), 1659-1700.

Talmy, L. (1994). The windowing of attention in language. In M. Shibatani \& S. Thompson (eds). Essays in semantics. Oxford: Oxford University Press.

Talmy, L. (2000). Toward a cognitive semantics. Cambridge, MA: MIT Press.

Thierry, G. (2016). Neurolinguistic relativity: HHow language flexes human perception and cognition. Language Learning 66(3), 690-713.

Tomasello, M. (2006). Acquiring linguistic constructions. In D. Kuhn, R. S. Siegler, W. Damon \& R. M. Lerner (eds), Handbook of child psychology: cognition, perception, and language (pp. 255-298), Hoboken, NJ: John Wiley \& Sons.

Tremblay, A., Derwing, B., Libben, G. \& Westbury, C. (2011). Processing advantages of lexical bundles: evidence from self-paced reading experiments, word and sentence recall tasks, and offline semantic ratings. Language Learning 61(2), 569-613.

Tummers, J., Heylen, K. \& Geearts, D. (2005). Usage-based approaches in Cognitive Linguistics: a technical state of the art. Corpus Linguistics and Linguistic Theory 1(2), 225-261.

Tyler, A. (2010). Usage-based approaches to language and their applications to second language learning. Annual Review of Applied Linguistics 30, 270-291. 
Vilkaitè, L. \& Schmitt, N. (2017). Reading collocations in an L2: Do collocation processing benefits extend to non-adjacent collocations? Applied Linguistics 40(2), 1-27.

Wullf, S. \& Ellis, N. C. (2018). Usage-based approaches to second language acquisition. In D. Miller, F. Bayram, J. Rothman \& L. Serratrice (eds), Bilingual cognition and language: The state of the science across its subfields (pp. 37-56). Amsterdam \& Philadelphia: John Benjamins.

Zacks, J. M. \& Tversky, B. (2001). Event structure in perception and conception. Psychological Bulletin 127(1), 3-21.

\section{Appendices}

Appendices A, B, and C can be found online at <https://doi.org/10.11588/ data/ZMWDP5>. 